\title{
What factors predict physicians' utilization behavior of contrast-enhanced ultrasound? Findings from a cross-sectional study in China
}

\author{
Qingwen Deng ${ }^{1}$ and Wenbin Liu $^{1}$ \\ ${ }^{1}$ Fujian Medical University
}

October 10, 2020

\begin{abstract}
Rationale, aims and objectives Given the importance of screening for liver cancer and the lack of relevant research, this study aims to investigate the factors influencing physicians' utilization behavior of contrast-enhanced ultrasound (CEUS) by verifying the proposed research hypotheses based on the integration of the Theory of Planned Behavior and Technology Acceptance Model. Methods A cross-sectional study was conducted in Fujian and Jiangxi province, where has a high and low incidence of liver cancer in China, respectively. Two medical consortiums were randomly selected from each province, and $50 \%$ of the medical institutions were randomly selected from each medical consortium. Physicians working in liver disease-related departments of the selected medical institutions were invited to participate in the questionnaire survey. Structural equation modeling was used to analyze the collected data. Results A total of 309 physicians were enrolled. The results showed that the research model fits the data well $(\chi 2 / \mathrm{df}=2.906$, CFI $=0.947$, TLI $=0.939$, and RMSEA $=0.079)$. Physicians' intention to use CEUS was directly associated with utilization behavior $(\beta=0.287, \mathrm{P}<0.001)$. Attitude $(\beta=0.272, \mathrm{P}<0.001)$, subjective norm $(\beta=0.172$, $\mathrm{P}<0.001)$, perceived behavioral control $(\beta=0.491, \mathrm{P}<0.001)$ and perceived usefulness $(\beta=0.108, \mathrm{P}<0.05)$ were significantly influence physicians' intention. Besides, subjective norm $(\beta=0.065, \mathrm{P}<0.05)$, perceived behavioral control $(\beta=0.141, \mathrm{P}<0.01)$, and perceived ease of use $(\beta=0.022, \mathrm{P}<0.05)$ indirectly affected physicians' utilization of CEUS. Conclusions The findings not only benefit expanding the knowledge of factors associated with physicians' utilization behavior of CEUS, but also have implications for promoting the utilization of CEUS and other health technologies, such as building innovative and incentive environment, mobilizing the senior physicians and managers, and providing high quality and adequate training.
\end{abstract}

\section{Hosted file}

Manuscript.pdf available at https://authorea.com/users/365957/articles/485871-what-factorspredict-physicians-utilization-behavior-of-contrast-enhanced-ultrasound-findings-from-across-sectional-study-in-china

\section{Hosted file}

Figure.pdf available at https://authorea.com/users/365957/articles/485871-what-factorspredict-physicians-utilization-behavior-of-contrast-enhanced-ultrasound-findings-from-across-sectional-study-in-china 